\title{
Criação e socialização do conhecimento: estudo com profissionais de controladoria e operações
}

\author{
Knowledge creation and socialization: study with controllership and operations \\ professionals
}

\section{Creación y socialización del conocimiento: estudio con profesionales del controla doria y} operaciones

\section{Dímitra Alectoridis}

Mestre em Controladoria e Finanças Empresariais pela Universidade Presbiteriana Mackenzie (UPM)

Professora do curso de Bacharelado em Ciências Contábeis presencial - Centro Universitário SENAC

Endereço: Av. Engenheiro Eusébio Stevaux, 823 - Santo Amaro

CEP: 04696-000 - São Paulo/SP - Brasil

E-mail: dimitra.alectoridis@sp.senac.br

Telefone: (11) 5682-7527

\section{José Carlos Tiomatsu Oyadomari}

Doutor em Ciências Contábeis pela Universidade de São Paulo (USP)

Professor do Programa de Pós-Graduação em Controladoria e Finanças Empresariais da Universidade Presbiteriana Mackenzie - Professor do Insper

Endereço: Rua da Consolação, 930 - Prédio 45 - Consolação

CEP: 01302-907 - São Paulo - SP - Brasil

E-mail: oyadomari@mackenzie.br

Telefone: (11) 2114-8273

\section{Welington Norberto Carneiro}

Mestre em Controladoria e Finanças Empresariais pela Universidade Presbiteriana Mackenzie (UPM)

Coordenador de Controladoria na General Mills

Endereço: Rua da Consolação, 930 - Prédio 45 - Consolação

CEP: 01302-907 - São Paulo - SP - Brasil

E-mail: welington_carneiro@yahoo.com.br

Telefone: (11) 2114-8273

\section{Maria Thereza Pompa Antunes}

Doutora em Ciências Contábeis pela Universidade de São Paulo (USP)

Coordenadora do Mestrado Profissional em Controladoria e Finanças Faculdade FIPECAFI

Endereço: Rua Maestro Cardim, $1170-8^{\circ}$ andar

CEP: 01323 - 001 São Paulo - SP - Brasil

E-mail: maria.antunes@fipecafi.org

Telefone: (11) 2184-5710

Artigo recebido em 08/01/2018. Revisado por pares em 05/04/2018. Reformulado em 03/05/2018. Recomendado para publicação em 15/06/2018 por Carlos Eduardo Facin Lavarda Editor-Chefe). Publicado em 30/06/2018. 


\title{
Resumo
}

Este estudo teve por objetivo avaliar a interação entre profissionais das áreas de contabilidade gerencial e de gestão de operações, sob a luz da teoria da criação de conhecimento na empresa, segundo Nonaka e Takeuchi. Para tanto, foram entrevistados nove profissionais de controladoria e nove de operações pares em suas empresas. Os resultados da pesquisa revelaram que esses profissionais buscam conhecimento em fontes externas, que compartilham esse conhecimento de maneira informal e que os resultados dessas interações são benéficos para a empresa, porém há ausência de orientação institucional por parte das empresas. A preocupação com a perda do poder foi apontada como causa que dificulta a interação, mas que a informalidade pode contribuir para minimizar esse efeito. $O$ estudo também mostrou que há necessidade de um entendimento dos negócios por parte dos profissionais de controladoria, e paralelamente, uma necessidade que os profissionais de operações entendam os impactos financeiros de suas decisões. O estudo contribuiu com a teoria e prática em apresentar e validar o modelo SECI aplicado aos profissionais de controladoria e operações e, também, ao analisar em profundidade como ocorre essa interação e, ainda, mostrando que existem sensíveis dificuldades na criação do conhecimento empresarial.

Palavras-chave: Conhecimento; Controladoria; Nonaka e Takeuchi; SECI; Operações

\begin{abstract}
The purpose of this study was to evaluate the interaction between professionals in the areas of managerial accounting and operations management, in light of the theory of knowledge creation in the company, by Nonaka e Takeuchi We interviewed 9 controllers and 9 operations professionals. The results of the research demonstrated that these professionals seek knowledge from outside sources and share this knowledge informally. The results of these interactions are beneficial to the company, but there is a lack of an institutional orientation of the company. One factor that has disrupted this interaction is concern about loss of power, but initiatives that promote informal interaction facilitate this process. The study contributes with the theory and practice showing and validating the SECI framework applied to professional on management accounting and operations also analyzing deeply how occur the interaction and showing that there are sensible difficulties on the creation of knowledge. The study also showed that there is a need for an understanding of business by controllers, and in parallel, a need for operations professionals to understand the financial impacts of their decisions.
\end{abstract}

Keywords: Knowledge; Controllership; Nonaka \& Takeuchi; SECI; Operations

\section{Resumen}

Eso estudio tuvo como objetivo hacer una analice entre los profesionales de las áreas de contabilidad gerencial y de gestión de operaciones, a la luz de la teoría da creación del conocimiento en la empresa, por Nonaka y Takeuchi. Fueran entrevistados 9 profesionales del controla doria y 9 de operaciones. Los resultados de la pesquisa demostraran que esos profesionales buscan conocimiento en fuentes externas y dividen eso conocimiento de modo informal. Los resultados de las interacciones son benéficos para la empresa, todavía hay una carencia de una orientación institucional de la empresa. Un factor que ten desordenado esa interacción es la preocupación con la pierda de poder, todavía iniciativas que promulgan la interacción informar facilita eso proceso. Lo estudio contribuí con la teoría y práctica en presentar y validar el modelo SECI aplicado a los profesionales de controla doria $y$ de operaciones y también a analizar en profundidad como ocurre la interacción y mostrando que aún existen sensibles dificultades en la creación del conocimiento empresarial. Lo estudio también mostró que hay necesidad de uno entendimiento de los negocios por parte de los profesionales de controla doria y paralelamente, una necesidad que los profesionales de operaciones entendian los impactos financieros de sus decisiones.

Palabras clave: Conocimiento; Controladoria; Nonaka y Takeuchi; SECI; Operaciones 


\section{Introdução}

Os profissionais de controladoria têm sido bastante criticados pelo pouco envolvimento com os negócios da empresa (Bartel \& Dutton, 2001; Caldwell, 2003; Wright, 2009). Porém, atualmente, a literatura acadêmica tem enfatizado o papel do controller como business partner (Byrne \& Pierce, 2007; Davis \& Mclaughlin, 2009), e mesmo a literatura de negócios (Grundy, 2016), muito embora os resultados no Brasil mostram que o perfil que representa a maior parcela dos controllers seja do tipo bean counter (Souza, 2016).

Para que os controllers apoiem as áreas de negócios, gerando conhecimento que possa ser compartilhado, é necessário que ocorra a interação com os profissionais dessas áreas, uma vez que o ambiente de trabalho é caracterizado pela interação entre as pessoas (Hu \& Shi, 2015). Embora se reconheça isso, pouco tem sido pesquisado sobre a interação dos empregados com seus pares internos (Grandey, 2003; Hülsheger \& Schewe, 2011).

De acordo com Nonaka \& Takeuchi (1997), a geração de conhecimento organizacional é afetada pela condição humana de aprendizado e proatividade e, também, pelas oportunidades e necessidades geradas pelo ambiente e por situações específicas. Nas empresas, a capacidade de gerar conhecimento através de grupos de gestão é algo relativamente novo e existente em tipos específicos de empresas que compreendem sua importância (Davenport \& Prusak, 1998).

Nonaka e Takeuchi (1997) também afirmam que a organização não pode criar o conhecimento sem os indivíduos, e se este conhecimento não puder ser compartilhado, não há desenvolvimento da organização. Assim, é essencial identificar a forma (ou formas) sob a qual o conhecimento é construído e, para tanto, desenvolveram um modelo denominado por modelo SECI - Socialização, Externalização, Combinação, Internalização, o qual representa a combinação de dois tipos de conhecimento: o tácito e o explícito.

Apesar da importância de se gerar e disseminar o conhecimento nas organizações, poucos estudos na área de contabilidade gerencial no Brasil têm se debruçado sobre como isso ocorre entre os profissionais de controladoria, sendo uma exceção o trabalho de Simãozinho, Oyadomari, Barros, Akami e Antunes (2015), muito embora que nesse estudo os autores não tenham avaliado a interação com profissionais de outra área. Outra exceção é o trabalho de Marques e Rocha (2017), os quais estudaram a criação de conhecimento sobre target costing, com base na análise da literatura.

Nesse contexto, entende-se que um dos pares internos com quem os controllers interagem, ou deveriam interagir, são os profissionais de operações, os quais são responsáveis pelas ações que possibilitam alcançar os resultados, ao coordenarem os ciclos de vida dos negócios visando otimiza-los quando possível (Tazelaar \& Snijders, 2013). Da mesma forma, eles lidam com temas que impactam de forma significativa o resultado operacional, particularmente em relação à rubrica custos dos produtos vendidos e, também, do capital investido, no tocante aos estoques e ativos imobilizados. Importante ressaltar também que esta área é reconhecida como desenvolvedora de inovações e ferramentas de gestão e controle, tais como Lean Manufacturing, Six Sigma, Total Quality Management, MRP, Value Chain, etc. (Krajewski, Ritzman \& Malhotra, 2010; Martins \& Laugeni, 2010), as quais são consideradas como a materialização do conhecimento organizacional (Davenport \& Prusak, 1998).

A despeito da importância de outros profissionais, a exemplo dos da área de vendas, por influenciarem as linhas de receitas e despesas com vendas, e dos das áreas administrativas que influenciam a linha de despesas gerais e administrativas, este estudo teve como objeto de investigação os profissionais de controladoria e operações com o objetivo de conhecer como eles interagem na criação e socialização do conhecimento, à luz do Modelo SECI (Socialização, Externalização, Combinação e Internalização) de Nonaka e Takeuchi (1997). Para tanto, parte-se da premissa de que o conhecimento gerado pela experiência e 
treinamento, e criado por especialistas, é extremamente complexo e de difícil gestão para as firmas, conforme apontam Abernethy, Horne, Lillis, Malina e Selto (2005).

Entende-se que este estudo traz importantes contribuições para a literatura e para a prática. Primeiramente, por apresentar e validar o modelo SECI (Socialização, Externalização, Combinação e Internalização) aplicado aos profissionais de controladoria e operações. Da mesma forma, devido a sua profundidade, visto ter analisado como ocorre na prática essa interação entre esses profissionais e, ainda, como o conhecimento é por eles gerado e retroalimentado, mostrando que ainda existem sensíveis dificuldades na criação do conhecimento organizacional.

\section{Referencial Teórico}

\subsection{Interação entre Profissionais de Gestão de Operações e Profissionais de Contabilidade Gerencial - gap entre a prática e a literatura}

Os profissionais da gestão de operações trabalham com conceitos práticos que evoluíram até a atualidade através da administração de produção, a qual é definida como o estudo de um conjunto de atividades que transformam um bem tangível em outro com uma utilidade mais elaborada (Martins \& Laugeni, 2010). Krajewski, Ritzman e Malhotra (2010) ampliam essa definição ao afirmarem que a administração de operações se relaciona com projeto, direção e controle de processos, que transformam insumos em serviços e produtos para clientes internos e externos.

Em operações, tem-se, também, o fator humano (Drejer, Blackmon \& Voss, 1998), uma vez que esse campo difere muito de outras áreas, porque relaciona-se com os elementos físicos e com o elemento humano. Em adição aos elementos 'pesados' da área - como a própria gestão da operação - muitos pesquisadores têm focado na questão humana e as pesquisas que incluem tais elementos humanos em operações tem tido uma tradição forte nos estudos escandinavos (Drejer, Blackmon \& Voss, 1998).

Em termos da utilidade da informação da contabilidade gerencial para tomada de decisão em seus departamentos, a maior parte dos gestores de operações concorda com que essas informações sejam de fato úteis, segundo pesquisa realizada em 2008 com membros da The Association for Operations Management (APICS). Adicionalmente, esta pesquisa mostrou ainda que há necessidade de se ampliar o engajamento entre as áreas técnica e contábil, através da demanda de informações por parte das áreas técnicas, por esses relatórios gerenciais. (Conrman, 2008).

Muito embora seja essa uma demanda identificada por profissionais atuantes na prática, nota-se que as pesquisas acadêmicas não têm abordado esse tema. Esse fato pode ser verificado por meio de um levantamento realizado no principal periódico da área de operações, o Journal of Operations Management (Meredith, Steward, \& Lewis, 2011), por meio dos termos Accounting, Management Accounting, Operations Management and Accounting ou Finance, em artigos publicados no período de 2013 a 2017 tendo sido encontrado apenas 1 (um) artigo que cita o profissional de contabilidade gerencial como sendo importante para o desenvolvimento do gerenciamento das operações (Fullerton, Kennedy \& Widener, 2014). A mesma pesquisa foi feita no periódico Management Accounting Research, sendo verificadas as citações dos termos Operations e Operations Management, nos artigos publicados também no período de 2013 a 2017, não tendo sido encontrado nenhum resultado.

Por outro lado, encontram-se alguns autores que argumentam que a interação entre esses dois profissionais deva se dar por meio de um comportamento mais brando, pois consideram o mais propício no processo de influenciar os gestores de operações a tomarem certas medidas 
desejáveis pela liderança (Mack, Simone; \& Goretzki, 2011).Outros autores, por sua vez, consideram que, quando um profissional de controladoria adota uma posição neutra, ou apenas fornecendo informação (Donoghue; Fayard \& Brigham, 1998), a sua postura pode ser considerada desalinhada com as novas demandas exigidas desse profissional (Burns \& Baldvinsdottir, 2005; Järvenpää, 2007), as quais enfatizam os contadores gerenciais devam assumir a função de suporte à tomada de decisão, orientada para o negócio (Ahrens \& Chapman, 2002; Grandlund \& Lukka, 1998; Hopper, 1980).

A proximidade física dos controllers também tem sido apontada como um importante fator para que ocorra uma interação mais efetiva, pois as pesquisas indicam que quando contadores gerenciais estão mais próximos das unidades de negócios, esses são mais aceitos (Järvenpää, 2009) em vez dos profissionais que atuam na matriz das organizações (Grandlund \& Lukka, 1998; Järvenpää, 2007; Paulsson, 2012).

Embora os autores supracitados indiquem que ao trabalharem juntos (contadores e profissionais de operações) os conflitos de interesses podem surgir como, por exemplo, quando os controllers reportem a folga orçamentária, ou evitam relatar problemas graves, dando mais tempo para gestores operacionais corrigirem os problemas (Fauré \& Rouleau, 2011; Lambert \& Sponem, 2005), a tendência de trabalharem juntos é tida como um progresso inegável (Morales \& Lambert, 2013).

\subsection{Gestão do Conhecimento}

Um dos modelos mais difundido de construção de conhecimento é o desenvolvido por Nonaka e Takeuchi (1997), no qual os autores demonstram que a construção do conhecimento se dá sob dois tipos de conhecimento: o conhecimento explícito e o conhecimento tácito, cuja diferenciação é expressada por Antunes (2004):

O conhecimento explícito é aquele sistematizado, materializado, fruto do trabalho de um indivíduo e que está prontamente disponível para ser transmitido e adquirido indistintamente e, nesse sentido, assume-se como sinônimo de informação. O conhecimento tácito, por sua vez, abrange as habilidades desenvolvidas em termos de know-how adquirido mais as percepções, crenças e valores que o indivíduo toma como certas e que refletem na imagem de como ele vê e interpreta a realidade, moldando a forma como percebe e lida com o mundo". (2004, p.19),

Na diferenciação supracitada, pode-se verificar que existe a interação entre os dois tipos de conhecimentos, dada a conversão de um (explicito) no outro (tácito), que ocorre por meio das habilidades individuais na observação dos participantes, ou seja, das pessoas nas organizações.

Os modos de conversão de conhecimento são representados, graficamente, por Nonaka e Takeuchi (1997, p. 81), o qual propõe quatro formas de conversão de conhecimento, assumindo que o conhecimento é criado na organização a partir do conhecimento tácito e explícito existente nela. Assim, cada quadrante representa um processo específico que passa a outro de forma ordenada, mas ao mesmo tempo infinita, partindo do indivíduo, chega ao grupo (socialização), transforma-se em conhecimento reconhecido (externalização), impacta no grupo (combinação) e atinge novamente o indivíduo (internalização), transformando o ambiente (empresa). A Figura 1 expõe esse mecanismo. 


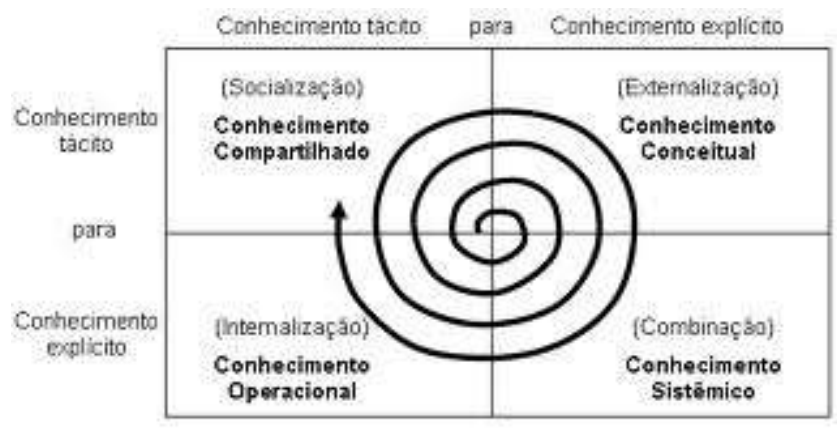

Figura 1. Conteúdo do conhecimento criado pelos quatro modos Fonte: Nonaka e Takeuchi, 1997, p.81.

A Figura 2 exemplifica a geração de conhecimento organizacional ao apresentar um resumo dos modos de conversão, demonstrando os elementos de transição entre os modos, seu conceito e características, além de ferramentas necessárias para a existência e desenvolvimento do processo.

\begin{tabular}{|c|c|c|c|c|}
\hline & $\begin{array}{l}\text { Elemento de } \\
\text { transição }\end{array}$ & Modo de conversão & Característica & $\begin{array}{l}\text { Ferramentas } \\
\text { conversão }\end{array}$ \\
\hline \multirow{5}{*}{ 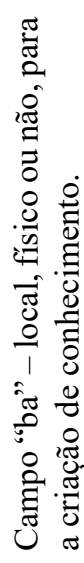 } & Indivíduo & \multirow{2}{*}{$\begin{array}{l}\text { Socialização } \\
\text { (Inicia com o indivíduo, precisa de } \\
\text { esforço conjunto e participação dos } \\
\text { envolvidos). }\end{array}$} & \multirow[t]{2}{*}{$\begin{array}{l}\text { Tácito para } \\
\text { tácito }\end{array}$} & \multirow[t]{2}{*}{$\begin{array}{l}\text { Brainstorming } \\
\text { Experiência individual } \\
\text { observada }\end{array}$} \\
\hline & Diálogo & & & \\
\hline & \multirow{2}{*}{$\begin{array}{l}\text { Associação do } \\
\text { conhecimento } \\
\text { explícito }\end{array}$} & $\begin{array}{l}\text { Externalização } \\
\text { (Trabalho conjunto combinando } \\
\text { indução e dedução - modelagem do } \\
\text { conhecimento para a empresa) }\end{array}$ & $\begin{array}{l}\text { Tácito para } \\
\text { explícito }\end{array}$ & $\begin{array}{l}\text { Metáfora, analogia, } \\
\text { modelo. }\end{array}$ \\
\hline & & $\begin{array}{l}\text { Combinação } \\
\text { (Sistematização do conceito através } \\
\text { de ferramentas administrativas) }\end{array}$ & $\begin{array}{l}\text { Explícito para } \\
\text { explícito }\end{array}$ & $\begin{array}{l}\text { Documentos, reuniões, } \\
\text { rede de informações. }\end{array}$ \\
\hline & $\begin{array}{l}\text { Aprender } \\
\text { fazendo }\end{array}$ & $\begin{array}{l}\text { Internalização } \\
\text { (Volta o indivíduo, para apreender o } \\
\text { conhecimento). }\end{array}$ & $\begin{array}{l}\text { Explícito para } \\
\text { tácito }\end{array}$ & $\begin{array}{l}\text { Aprender fazendo, } \\
\text { reexperimentar, ouvir } \\
\text { histórias reais. }\end{array}$ \\
\hline
\end{tabular}

Figura 2. Resumo dos modos de conversão do conhecimento

Fonte: Desenvolvido pelos autores, 2017.

Para a criação de conhecimento organizacional é necessário a existência de condições propícias, sendo que Nonaka e Takeuchi (1997) as descrevem como intenção (justificativo presente no indivíduo e na empresa); autonomia (liberdade para gestor) flutuação e caos criativo (problemas reais e colapso de rotinas); redundância (acesso a banco de dados com duplicidade de informações) e variedade de requisitos (combinação de experiências entre grupos complexos).

Para se avaliar a construção de conhecimento nas organizações faz-se necessário mensurar as fases dessa criação, descritas como: compartilhamento de conhecimento tácito; criação de conceitos; justificação de conceitos; construção de arquétipo e nivelação de conhecimento (Nonaka \& Takeuchi, 1997).

Por fim, vale mencionar que para a criação do conhecimento nas organizações, nem sempre significa seguir um plano passo a passo, mas, sim, desenvolver as iniciativas conforme sua utilidade em partes específicas do espiral do conhecimento (Sabbag, 2007). Desse modo, 
incentivar as iniciativas existentes é um bom passo estratégico para o início da construção do conhecimento nas empresas.

\section{Procedimentos Metodológicos}

Este estudo descritivo e de natureza qualitativa foi desenvolvido junto à profissionais das áreas de contabilidade e de operações, por meio da realização de entrevistas. As pesquisas qualitativas propiciam as análises mais profundas em relação ao fenômeno estudado (Beuren, 2012) possibilitando encontrar evidências suficientes e sustentar afirmações apresentadas pelos entrevistados. (Booth, Colomb \& Williams, 2005).

Para tanto, foi desenvolvido um protocolo de pesquisa, cujas questões (roteiro de entrevista) foram criadas pelos autores, a partir de Nonaka e Takeuchi (1997). A Figura 3 apresenta este documento, correlacionando as questões à base teórica utilizada e ao que se pretende avaliar.

Vale observar que na condução das entrevistas foram feitos questionamentos complementares às respostas, de modo a caracterizar uma oportunidade de mensuração, sempre que oportuno.

\begin{tabular}{|c|c|c|c|}
\hline $\mathbf{N}^{\mathbf{0}}$ & Questões & Base teórica & O que se pretende medir \\
\hline \multirow[t]{2}{*}{3} & \multirow{2}{*}{\begin{tabular}{|l|} 
Você já tentou \\
implementar \\
alguma ferramenta \\
de controle? \\
Identificou \\
resistências? \\
\end{tabular}} & \multirow[t]{2}{*}{2 - Socialização } & $\begin{array}{l}\text { 2a) Identificar a proatividade do profissional em implementar novas } \\
\text { ferramentas de controle, mostrando maturidade do conhecimento } \\
\text { individual e interesse pela melhoria contínua do processo }\end{array}$ \\
\hline & & & $\begin{array}{l}\text { 2b) Identificar se houve resistência, de quem e como o profissional } \\
\text { resolveu a questão. }\end{array}$ \\
\hline \multirow[t]{2}{*}{4} & \multirow{2}{*}{$\begin{array}{l}\text { Em relação à sua } \\
\text { área de atuação, } \\
\text { como você adquire } \\
\text { informações? }\end{array}$} & \multirow{2}{*}{$\begin{array}{l}\text { 1-Conhecimento } \\
\text { individual }\end{array}$} & $\begin{array}{l}\text { 1a) identificar quais são os métodos que o entrevistado utiliza para a } \\
\text { criação de conhecimento individual, seu desenvolvimento como } \\
\text { profissional e como gestor. }\end{array}$ \\
\hline & & & $\begin{array}{l}\text { 1b) quais são suas principais fontes de informação para seu } \\
\text { desenvolvimento profissional individual. }\end{array}$ \\
\hline \multirow[b]{2}{*}{5} & \multirow{2}{*}{\begin{tabular}{|lr|} 
Como & você \\
converte & essas \\
informações & em \\
conhecimento a & ser \\
utilizado & na \\
empresa por & você e \\
\multicolumn{2}{|l}{ sua equipe? } \\
\end{tabular}} & \multirow[b]{2}{*}{$\begin{array}{l}\text { 1-Conhecimento } \\
\text { individual }\end{array}$} & $\begin{array}{l}\text { 1c) medir quanto o entrevistado compreende a diferença entre } \\
\text { informação e conhecimento }\end{array}$ \\
\hline & & & $\begin{array}{l}\text { 1d) identificar a maturidade do conhecimento individual, sua } \\
\text { importância para o profissional e a base que gera conhecimento } \\
\text { tácito. }\end{array}$ \\
\hline \multirow{3}{*}{6} & \multirow{3}{*}{$\begin{array}{l}\text { Como você } \\
\text { compartilha esses } \\
\text { conhecimentos com } \\
\text { seus pares e os } \\
\text { profissionais do } \\
\text { departamento B? }\end{array}$} & \multirow{3}{*}{2 - Socialização } & $\begin{array}{l}\text { 2c) verificar se existe uma preocupação do entrevistado em transferir } \\
\text { seus conhecimentos individuais aos demais (tácito). }\end{array}$ \\
\hline & & & $\begin{array}{l}\text { 2d) saber qual a forma utilizada por ele para transmitir esse } \\
\text { conhecimento ao departamento B. }\end{array}$ \\
\hline & & & $\begin{array}{l}\text { 2e) verificar se há uma equipe auto organizada na transmissão de } \\
\text { conhecimento, além de intenção e valorização da autonomia na } \\
\text { criação de ideias. }\end{array}$ \\
\hline \multirow[b]{2}{*}{7} & \multirow{2}{*}{\begin{tabular}{|l|} 
A empresa na qual \\
você trabalha \\
incentiva a partilha \\
de conhecimentos \\
entre sua área e o \\
departamento B? \\
Como?
\end{tabular}} & \multirow[b]{2}{*}{2 - Socialização } & $\begin{array}{l}\text { 2f). Verificar se a empresa percebe valor no conhecimento individual } \\
\text { de modo a justificar a necessidade de seu compartilhamento. }\end{array}$ \\
\hline & & & $\begin{array}{l}2 \mathrm{~g} \text { ) avaliar a intenção organizacional e seu incentivo à criação do } \\
\text { conhecimento. }\end{array}$ \\
\hline
\end{tabular}




\begin{tabular}{|c|c|c|c|}
\hline \multirow{3}{*}{8} & \multirow{3}{*}{ 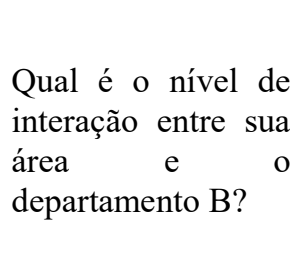 } & \multirow{3}{*}{$\begin{array}{l}\text { 6-Construção do } \\
\text { conhecimento } \\
\text { empresarial }\end{array}$} & $\begin{array}{l}\text { 6a) Identificar algum padrão ou modelo para que a criação do } \\
\text { conhecimento seja representativa nas relações entre os } \\
\text { departamentos }\end{array}$ \\
\hline & & & $\begin{array}{l}\text { 6b) identificar a possibilidade de criação futura de um modelo de } \\
\text { criação de conhecimento. }\end{array}$ \\
\hline & & & 6c) verificar interação de profissionais entre departamentos. \\
\hline \multirow{4}{*}{9} & \multirow{4}{*}{$\begin{array}{l}\text { Com que frequência } \\
\text { e em quais situações } \\
\text { vocês trocam } \\
\text { conhecimento? }\end{array}$} & \multirow{4}{*}{$\begin{array}{l}\text { 6-Construção do } \\
\text { conhecimento } \\
\text { empresarial }\end{array}$} & 6d) Identificar a motivação da interação entre os departamentos. \\
\hline & & & $\begin{array}{l}\text { 6e) Identificar se há intenção no processo, se o campo ("ba") é } \\
\text { específico para a criação de conhecimento ou se a criação ocorre } \\
\text { apenas em momentos de crise. }\end{array}$ \\
\hline & & & $\begin{array}{l}\text { 6f) identificar situações específicas que geram interação - caos } \\
\text { criativo }\end{array}$ \\
\hline & & & $\begin{array}{l}6 \mathrm{~g} \text { ) identificar a criação de conhecimento em momentos de colapso } \\
\text { criados pelas situações reais ou por situações artificiais, de modo a } \\
\text { medir se há movimento de "ordem a partir do caos". }\end{array}$ \\
\hline \multirow[t]{2}{*}{10} & \multirow{2}{*}{$\begin{array}{l}\text { Qual é a intensidade } \\
\text { dessa interação, e a } \\
\text { importância dela } \\
\text { para você? }\end{array}$} & \multirow[t]{2}{*}{ 3- Externalização } & $\begin{array}{l}\text { 3a) Verificar o nível de solicitude individual para a construção de } \\
\text { conhecimento: compreensão da existência de compartilhamento por } \\
\text { confiança ou falta dela por algum tipo de receio. }\end{array}$ \\
\hline & & & $\begin{array}{l}\text { 3b) Verificar a importância da interação para o entrevistado, } \\
\text { observando algum exemplo importante. }\end{array}$ \\
\hline \multirow[b]{2}{*}{11} & \multirow{2}{*}{$\begin{array}{l}\text { Como você avalia o } \\
\text { quão produtivo é } \\
\text { esta interação? }\end{array}$} & \multirow[b]{2}{*}{ 5- Internalização } & $\begin{array}{l}\text { 5a) Verificar o grau de sinergia que pode existir entre os profissionais } \\
\text { das áreas. }\end{array}$ \\
\hline & & & $\begin{array}{l}\text { 5b) verificar se há intenção de combinar as experiências entre os } \\
\text { departamentos para ampliar a construção de conhecimento e a } \\
\text { internalização (variedade de requisitos). }\end{array}$ \\
\hline \multirow[t]{2}{*}{12} & \multirow{2}{*}{$\begin{array}{lr}\text { Você pode } & \text { me } \\
\text { contar } & \text { alguns } \\
\text { resultados } & \text { dessas } \\
\text { interações } & \text { com } \\
\text { algum exemplo? }\end{array}$} & \multirow[t]{2}{*}{ 5- Internalização } & $\begin{array}{l}\text { 5c) Identificar a transmissão de conhecimento pelo método de } \\
\text { "aprender fazendo", de modo a reforçar a absorção do conhecimento } \\
\text { do grupo para o indivíduo. }\end{array}$ \\
\hline & & & $\begin{array}{l}\text { 5d) verificar se o método utilizado para essa transmissão de } \\
\text { conhecimento promove internalização }\end{array}$ \\
\hline \multirow[b]{2}{*}{13} & \multirow{2}{*}{$\begin{array}{lr}\text { Alguma demanda } \\
\text { de sua área já foi } \\
\text { solucionada } r \text { pela } \\
\text { área B, trazendo } \\
\text { alterações } & \text { aos } \\
\text { processos? } & \text { Pode } \\
\text { citar } & \text { algum } \\
\text { exemplo? } & \\
\end{array}$} & \multirow[b]{2}{*}{ 3- Externalização } & $\begin{array}{l}\text { 3c) Verificar se há transformação dos conhecimentos individuais em } \\
\text { coletivos. }\end{array}$ \\
\hline & & & $\begin{array}{l}\text { 3d) verificar o uso da reflexão em grupo e construção de modelos } \\
\text { para externalizar o processo. }\end{array}$ \\
\hline \multirow[b]{2}{*}{14} & \multirow{2}{*}{$\begin{array}{l}\text { Seu departamento e } \\
\text { o departamento B } \\
\text { compartilham } \\
\text { procedimentos de } \\
\text { atividades de suas } \\
\text { áreas? Como isso } \\
\text { ocorre? }\end{array}$} & \multirow[b]{2}{*}{4 - Combinação } & $\begin{array}{l}\text { 4a) Observar se há existência de interação de conhecimentos } \\
\text { explícitos entre os departamentos }\end{array}$ \\
\hline & & & $\begin{array}{l}\text { 4b) verificar a construção de conhecimento explícito entre grupos } \\
\text { distintos na empresa. }\end{array}$ \\
\hline 15 & $\begin{array}{l}\text { Você acredita que } \\
\text { conhecer as tarefas }\end{array}$ & 4 - Combinação & $\begin{array}{l}\text { 4c) Identificar a existência de redundância de informações } \\
\text { disponíveis }\end{array}$ \\
\hline
\end{tabular}




\begin{tabular}{|c|c|c|c|}
\hline & $\begin{array}{l}\text { do departamento B } \\
\text { pode ser importante } \\
\text { para criação de } \\
\text { conhecimento no } \\
\text { seu departamento? } \\
\text { Por quê? }\end{array}$ & & $\begin{array}{l}\text { 4d) verificar a percepção dos respondentes sobre a utilidade da } \\
\text { disponibilização indiscriminada de dados para gerar criação de } \\
\text { conhecimento futuro. }\end{array}$ \\
\hline 16 & $\begin{array}{l}\text { Você acredita que o } \\
\text { Departamento de } \\
\text { Operações assumiu } \\
\text { o trabalho da } \\
\text { Controladoria? }\end{array}$ & $\begin{array}{l}\text { 6-Construção do } \\
\text { conhecimento } \\
\text { empresarial }\end{array}$ & 6h). Verificar se há inversão de papéis \\
\hline \multirow[b]{2}{*}{17} & \multirow{2}{*}{\begin{tabular}{lr}
\multicolumn{3}{l}{ Para você, quais são } \\
as barreiras que \\
impedem \\
construção \\
conhecimento entre \\
os departamentos?
\end{tabular}} & \multirow[b]{2}{*}{ 3- Externalização } & $\begin{array}{l}\text { 3e) reconhecer se existem barreiras para a construção de } \\
\text { conhecimento entre as áreas }\end{array}$ \\
\hline & & & $\begin{array}{l}\text { 3f) identificar as principais barreiras que impedem a construção de } \\
\text { conhecimento }\end{array}$ \\
\hline \multirow[b]{2}{*}{18} & $\begin{array}{l}\text { O que a construção } \\
\text { de conhecimento }\end{array}$ & \multirow[b]{2}{*}{$\begin{array}{l}\text { 6-Construção do } \\
\text { conhecimento } \\
\text { empresarial }\end{array}$} & $\begin{array}{l}\text { 6i) identificar existência de melhoria na empresa quando há } \\
\text { construção de conhecimento }\end{array}$ \\
\hline & $\begin{array}{l}\text { compartilhada pode } \\
\text { melhorar nas } \\
\text { atividades da } \\
\text { empresa? }\end{array}$ & & $\begin{array}{l}\text { 6j) identificar se a empresa tem a preocupação estratégica em } \\
\text { construir conhecimento ou se os funcionários a tem. }\end{array}$ \\
\hline
\end{tabular}

Figura 3. Roteiro de questões referenciado com a teoria e objetivos - base para mensuração das respostas Nota. Não contempla as questões sobre identificação geral, por isso a numeração começa na $3^{\mathrm{a}}$. Questão.

Fonte: Desenvolvido pelos autores, 2017.

Com base em critérios de acessibilidade, foram entrevistados 18 profissionais das áreas de contabilidade gerencial e de gestão de operações, sendo 9 (nove) respondentes de cada área, que atuam na mesma empresa, portanto, trabalhou-se com uma amostra caraterizada de conveniência.

De forma a garantir a qualidade dos dados, buscaram-se profissionais com mais de 3 (três) anos de experiência na função, maduros em suas posições de decisão, com experiência em gestão de equipes e com relações constantes com o departamento parceiro na pesquisa, garantindo vivência suficiente para possibilitar respostas ricas à proposta deste estudo.

As respostas foram analisadas por meio da técnica de Análise de Conteúdo, a mais indicada para estudos de natureza qualitativa e cujos dados foram coletados por meio de entrevistas. Para tanto, fez-se uso do o software NVIVO, que é uma ferramenta de análise de dados qualitativos (Computer Assisted Qualitative Data Analysis Software - CAQDAS), a qual permite as análises de diferentes documentos em textos (a transcrição das entrevistas) e em outras fontes também (áudios, imagens e vídeos). Segundo Krippendorf (2013), esse software permite análises internas, reedição de documentos evitando, assim, retrabalho nessa etapa da pesquisa.

\section{Apresentação e discussão dos Resultados}

\subsection{Análise demográfica dos respondentes}

A Tabela 1 apresenta as características demográficas dos respondentes em termos de tempo na função e de setores sob suas responsabilidades.

Conforme já mencionado, foram entrevistados 18 profissionais, dois por empresa, atuantes nas áreas de controladoria e de operações, respectivamente. Esses respondentes representaram 9 (nove) empresas de setores como tecnologia (manufatura de componentes 
eletrônicos e itens de tecnologia eletroeletrônica e peças industriais de alta tecnologia) e manufatura de alimentos. Da mesma forma, pode-se verificar que a maioria desses profissionais é responsável por mais de um setor havendo, portanto, acumulo de responsabilidade.

A média de idade desses profissionais foi de 41 anos, e todos eles atuam há menos 5 anos na função dentro da mesma empresa, ou entre as duas últimas.

Vale mencionar que todos os profissionais demonstraram interesse na pesquisa, por compreenderem que a construção de conhecimento é aspecto fundamental para a melhoria do processo de gestão nas empresas e, também, que, muito embora o foco deste estudo tenha sido no profissional, pode-se verificar que as empresas nas quais atuavam, compreendiam a importância da estruturação da controladoria como departamento ou como conjunto de conhecimentos e que possibilitavam ou incentivavam seus profissionais a realizarem pesquisas acadêmicas.

Tabela 1

Características demográficas dos respondentes

\begin{tabular}{|c|c|c|c|c|}
\hline \multirow[b]{2}{*}{ Tempo de função (anos) } & \multicolumn{2}{|c|}{ Controladoria } & \multicolumn{2}{|l|}{ Operações } \\
\hline & Entre 3 e 5 & Mais de 5 & Entre 3 e 5 & Mais de 5 \\
\hline \multicolumn{5}{|l|}{ Ramo de atividade } \\
\hline Autopeças & 1 & 1 & 1 & 1 \\
\hline Indústria Eletroeletrônica & 1 & 1 & & 2 \\
\hline Peças industriais & & 1 & & 1 \\
\hline Tecnologia da informação & & 1 & & 1 \\
\hline Alimentos & 2 & 1 & 1 & 2 \\
\hline Total & 4 & 5 & 2 & 7 \\
\hline Setores de responsabilidade & \multicolumn{4}{|c|}{$\begin{array}{c}\text { Sobre total (considera gerência sobre mais de } \\
\text { um setor) }\end{array}$} \\
\hline Contabilidade- Fiscal & \multicolumn{2}{|c|}{$67 \%$} & & \\
\hline Controladoria - Contab. & & & \\
\hline Gerencial & & & & \\
\hline Custos & \multicolumn{2}{|c|}{$\begin{array}{l}44 \% \\
100 \%\end{array}$} & & \\
\hline Financeiro & \multicolumn{2}{|c|}{$44 \%$} & & \\
\hline Engenharia - Desenvolvimento & & & \multicolumn{2}{|c|}{$100 \%$} \\
\hline Gerenciamento de fábrica & & & \multicolumn{2}{|c|}{$78 \%$} \\
\hline Manutenção & & & \multicolumn{2}{|c|}{$56 \%$} \\
\hline Qualidade & & & \multicolumn{2}{|c|}{$56 \%$} \\
\hline
\end{tabular}

Fonte: Desenvolvido pelos autores, 2017.

\subsection{Análise de conteúdo}

No instrumento de coleta de dados (Figura 1) para cada questão determinou-se o que se pretendia medir (objetivo de cada questão). Assim, para se proceder à análise de conteúdo, foram criadas escalas em 3 (três) níveis: Alto, Médio ou Baixo. Nesse sentido, cada tipo de pergunta criada teve a intenção de observar a existência, ou não, de cada modo um dos modos de conversão para a construção do conhecimento, sendo o nível Alto como o de melhor avaliação quanto à possibilidade dessa construção.

Por exemplo, na questão de número 3 (três), cujo o objetivo era o de avaliar a proatividade do profissional em implementar novas ferramentas de controle (modo de conversão Socialização), a escala de referência foi: Alto - profissional proativo; Médio profissional com capacidade proativa verificada em poucas oportunidades e Baixo profissional não ativo neste quesito. 
Já para as questões formuladas, cujas respostas poderiam ser dadas de forma objetiva, criou-se a medida: Alto - sim; Médio - às vezes ou ocorreu uma vez; Baixo - não. Dessa forma, procurou-se atender as especificações de 3 (três) níveis no momento da análise das respostas, de modo que a análise textual se correlacionou com a técnica de mensuração proposta. A Figura 3 traz os quadrantes e os resultados obtidos através das entrevistas e posterior análise de conteúdo.

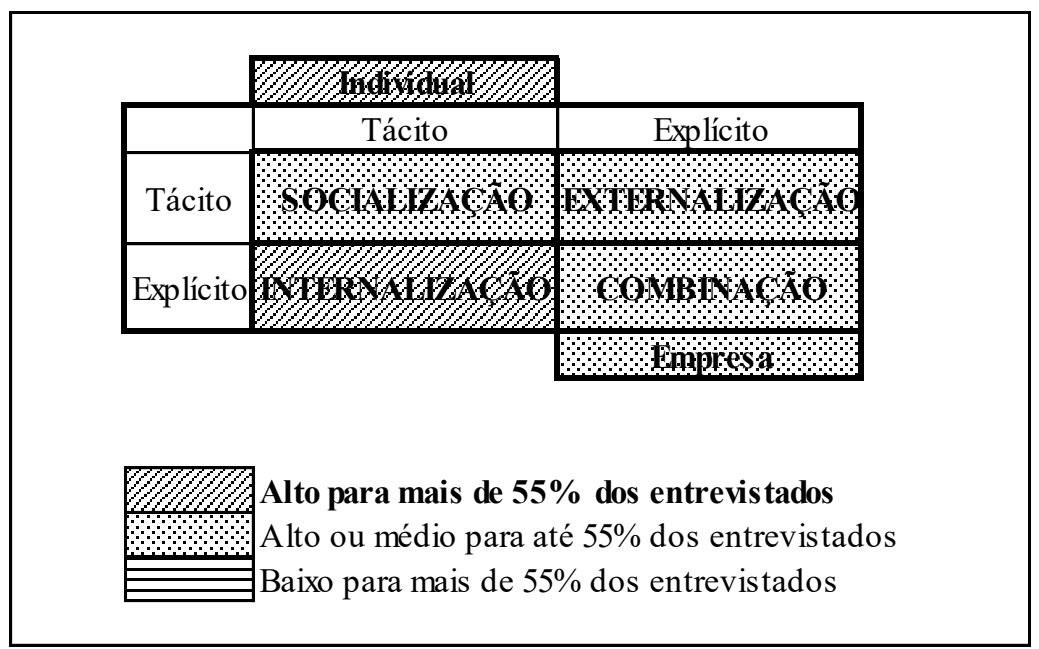

Figura 3. Resultado da maturidade da interação entre profissionais

Fonte: Desenvolvido pelos autores, 2017.

As marcas em destaque na Figura 3 representam a maturidade da criação de conhecimento de acordo com a avaliação da frequência em cada nível de resposta. Observa-se que apenas a criação de conhecimento individual e o modo de conversão internalização obtiveram nível alto, no âmbito de criação de conhecimento para mais da metade dos entrevistados. Ambos representam uma preocupação individual quanto ao conhecimento, o primeiro relacionado à percepção e criação de conhecimento para si, o outro revelando quanto os profissionais aproveitam os conhecimentos disponíveis para si e para a sua equipe realizarem melhor suas atividades nas empresas.

Os demais modos de conversão, incluindo o reconhecimento de criação de conhecimento na empresa, mostram que até a metade das avaliações das respostas dos entrevistados foram consideradas altas ou médias, indicando uma menor frequência de interação e maturidade nas ações diárias desses profissionais e empresas. As medidas consideradas medianas representam ações ou comportamentos que ocorrem às vezes, ou em função de uma pressão para resultado imediato, não sendo preocupações que justificam criação de conhecimento constante e independente.

\subsection{Modelo SECI}

\subsubsection{Conhecimento Individual}

A Tabela 2 apresenta a mensuração do conhecimento individual. A análise dos resultados permitiu verificar que $78 \%$ dos profissionais da área de controladoria se preocupam com a obtenção de conhecimento em sua área de atuação, principalmente em adquirir conhecimento em cursos externos sobre as normas internacionais de contabilidade. 
Tabela 2

Conhecimento Individual

\begin{tabular}{llr}
\hline Tipo & Profissional & Individual \\
\hline Alto & Controladoria & $\mathbf{7 8 \%}$ \\
Alto & Operações & $\mathbf{7 2 \%}$ \\
Médio & Controladoria & $19 \%$ \\
Médio & Operações & $25 \%$ \\
Baixo & Controladoria & $3 \%$ \\
Baixo & Operações & $3 \%$ \\
\hline
\end{tabular}

Fonte: Desenvolvido pelos autores, 2017.

Quanto à forma, vários citaram as reuniões internas como fonte de conhecimento, principalmente pela oportunidade do debate. Tais reuniões de alinhamento são importantes pois oportunidades de melhorias de processos, compartilhamento de conhecimento e solução de problemas (Gollan, Kalfa, Agarwal, Green \& Randhawa, 2014). Já os profissionais de operações ( $72 \%$ deles) demonstraram que o conhecimento individual oriundo de artigos técnicos e o conhecimento gerado por equipes internas de outras unidades fabris são mais efetivos.

Em síntese, pode-se afirmar que os profissionais das duas áreas de atuação conhecem a distinção entre informação e conhecimento, e consideram a criação de conhecimento como um fator importante para a tomada de decisão, porém, verificou-se que esta é focada na resolução de problemas. Esse achado difere do que afirmam Davenport e Prusak (1998), para quem os recursos dedicados ao conhecimento (pessoas que os multiplicam) são, por definição, ligeiramente distintos do trabalho cotidiano de uma organização que se preocupa muito mais com a informação.

Os trechos transcritos, a seguir, suportam a análise realizada:

Hoje a contabilidade está passando por diversas mudanças devido a normas internacionais de contabilidade, assim procuro sempre estar inteirada e ... fiz alguns cursos para minha atualização. Procuro também participar de grupos de discussão na internet e ler as notícias do Conselho de Contabilidade. Também leio artigos científicos e procuro discutir as novidades com os colegas, em especial com o Diretor de Controladoria" (Entrevistado 4, Controladoria).

O modelo da empresa em que trabalho, por ser de tecnologia, o pessoal de operações tem um cronograma mensal de educação continuada, que eles precisam cumprir essas horas. É o pessoal das frentes de trabalho, a base das operações. .... Já para o pessoal de staff, como é a minha área (BackOffice), a atualização é por sua conta, uma busca informações para sua atualização. Fazemos leituras regulares de jornais, IOB, discussões das maiores mudanças e notícias diárias. Procuramos se atualizar quanto a leis, medidas provisórias, fazemos curso na IOB para nos atualizarmos. (Entrevistado 5, Controladoria).

\subsubsection{Ferramentas de Gestão e Controle}

A Tabela 3 mostra as principais ferramentas de gestão usadas por esses profissionais e quais são consideradas necessárias para melhorar a atuação da empresa.

Os dados são apresentados cumulativamente, isto é, os entrevistados foram incentivados a citar todas as ferramentas utilizadas. A intenção foi justamente obter dos entrevistados uma lista de ferramentas utilizadas na gestão da empresa que, por fim, resultasse em um artefato final que deriva dos elementos completos que devem ser utilizados no controle gerencial que são: conceito, modelo, ferramenta e sistema de informação (Frezatti; Rocha; Nascimento \& Junqueira, 2009). 
Sendo o artefato um instrumento que possibilita a construção de conhecimento e interação entre profissionais, especialmente nos modos de conversão externalização e combinação, a análise dos resultados revelou que há instrumentos que possibilitam essa construção pela quantidade e diversidade de artefatos usados pelos entrevistados.

A Tabela 3 evidencia que $78 \%$ dos profissionais de controladoria fazem uso do Orçamento Empresarial como ferramenta de gestão, e para $67 \%$ deles não é necessário implantar novas ferramentas, mas, sim, utilizar melhor as já existentes. Para os profissionais de operações, os Indicadores de Performance são as ferramentas mais utilizadas, e também consideram que não é necessário implantar novas ferramentas, corroborando a percepção dos profissionais de controladoria na ênfase da melhoria na utilização.

Entende-se que esses resultados revelam que, de acordo com os profissionais respondentes, o estágio atual da prática apresenta uma oportunidade de melhorias incrementais, isto é, para o aperfeiçoamento do uso e, não, para a criação de novas ferramentas.

Tabela 3

Ferramentas de gestão atuais e necessárias

\begin{tabular}{|c|c|c|c|}
\hline \multicolumn{2}{|c|}{ Profissional de Controladoria } & \multicolumn{2}{|c|}{ Profissional de Operações } \\
\hline Ferramentas atuais & $\begin{array}{c}\text { S/ total de } \\
\text { entrevistados }\end{array}$ & Ferramentas atuais & $\begin{array}{c}\text { S/ total de } \\
\text { entrevistados }\end{array}$ \\
\hline $\mathrm{BSC}$ & $11 \%$ & Gestão de projetos & $11 \%$ \\
\hline Custo variável & $11 \%$ & Margem de contribuição & $11 \%$ \\
\hline Forecast & $11 \%$ & Sistema S\&OP & $11 \%$ \\
\hline Plano estratégico & $11 \%$ & Custo padrão & $44 \%$ \\
\hline Rolling forecast & $11 \%$ & Indicadores de qualidade & $78 \%$ \\
\hline Sistema S\&OP & $11 \%$ & Indicadores de performance & $89 \%$ \\
\hline Gestão de Projetos & $22 \%$ & & \\
\hline Fluxo de Caixa & $44 \%$ & & \\
\hline Custo padrão & $56 \%$ & & \\
\hline Custo por absorção & $56 \%$ & & \\
\hline $\begin{array}{l}\text { Indicadores de performance } \\
\text { Orçamento Empresarial / }\end{array}$ & $67 \%$ & & \\
\hline Budget & $78 \%$ & & \\
\hline Ferramentas necessárias & $\begin{array}{c}\text { S/ total de } \\
\text { entrevistados }\end{array}$ & Ferramentas necessárias & $\begin{array}{c}\text { S/ total de } \\
\text { entrevistados }\end{array}$ \\
\hline Balanced Scorecard & $11 \%$ & $\begin{array}{l}\text { Balanced Scorecard } \\
\text { Indicadores estatísticos }\end{array}$ & $11 \%$ \\
\hline Business Intelligence & $11 \%$ & para previsões futuras & $11 \%$ \\
\hline Custeio variável & $11 \%$ & Lean Manufacturing & $11 \%$ \\
\hline $\begin{array}{l}\text { Ferramenta para compreensão } \\
\text { do mercado }\end{array}$ & $11 \%$ & $\begin{array}{l}\text { Não há / usar melhor as } \\
\text { existentes }\end{array}$ & $67 \%$ \\
\hline $\begin{array}{l}\text { Não há / usar melhor as } \\
\text { existentes }\end{array}$ & $67 \%$ & & \\
\hline
\end{tabular}

\subsubsection{Socialização}

A Tabela 4 mostra os resultados obtidos em relação ao modo de conversão de socialização, o qual ocorre em função do indivíduo em direção ao grupo, sendo que neste estudo foi mensurada a proatividade para a criação de ferramentas de controle. 
Tabela 4

Socialização

\begin{tabular}{llr}
\hline Tipo & Profissional & Socialização \\
\hline Alto & Controladoria & $\mathbf{4 3 \%}$ \\
Alto & Operações & $\mathbf{5 4 \%}$ \\
Médio & Controladoria & $21 \%$ \\
Médio & Operações & $41 \%$ \\
Baixo & Controladoria & $37 \%$ \\
Baixo & Operações & $5 \%$ \\
\hline
\end{tabular}

Fonte: Desenvolvido pelos autores, 2017.

Os achados revelam que quando essa proatividade ocorre, para os profissionais de controladoria, esta é atribuída à indicação da matriz, enquanto que para os gestores de operações ela não ocorre por falta de necessidade, indicando uma satisfação com as ferramentas de controle atuais. Esses achados são contrários aos argumentos de Nonaka e Takeuchi (1997), para quem a intenção organizacional e a autonomia dos profissionais em se auto motivarem, são dois fatores importantes na criação de conhecimentos.

Um dado importante é o que mostra que $44 \%$ dos profissionais de controladoria não tem preocupação em compartilhar conhecimento, nem com seus pares, nem com os profissionais da área de operações, contrastando com os $78 \%$ dos profissionais de operações, que possuem interesse em partilhar. Para esses últimos, quanto mais as equipes puderem economizar tempo em função do conhecimento aplicado, mais produtiva a área de produção será.

Assim sendo, os profissionais de operações se mostraram mais abertos para a transmissão de conhecimentos aos seus próprios pares, mas também aos profissionais de controladoria, sendo que se identificaram várias citações indicando que há "economia de tempo quando todos conhecem as questões técnicas" e que "qualquer profissional pode ajudar a solucionar um problema". Em contrapartida, os profissionais de controladoria, não têm interesse em partilhar conhecimento com os profissionais de operações, pois na visão deles, aqueles que não têm "embasamento técnico adequado" sobre vários assuntos, como por exemplo questões legais envolvendo a contabilização dos custos, haveria "perda de tempo" nessa partilha de conhecimentos.

Esses achados revelam certo descasamento com a literatura mais recente em termos de melhoria de produtividade e processos, visto que ressaltam, por exemplo, a importância da divisão de conhecimento entre as áreas de negócios visando uma melhora no desempenho das empresas (Huange, Stewart \& Chen, 2009).

Os respondentes, entretanto, apontaram barreiras individuais e organizacionais como fatores que atrapalham a partilha de conhecimentos, consoante com o demonstrado no trabalho de Von Krogh, Ichio e Nonaka (2001), os quais indicam a incapacidade das pessoas em lidar com novas situações, na tentativa de manter-se na acomodação e proteção de sua autoimagem.

As análises das respostas também sugeriram potenciais situações conflituosas, como a exemplo da fala do Entrevistado 7 - Operações:

[...] a área de controladoria é considerada uma área burocrática, sendo que neles não existe o melhor dos relacionamentos, sendo a que controladoria age como juiz e quer controlar as ações das fábricas e isso não é visto como algo que ajuda, mas sim como algo que atrapalha, pois, o pessoal da fábrica se acha o ser mais importante da empresa. Já em uma empresa americana, onde eu já trabalhei anteriormente, a controladoria é vista como algo que pode ajudar pois a cultura de todos é voltada a compreender que finanças auxilia. (Entrevistado 7, Operações).

Mas um aspecto apontado para minimizar esses conflitos de interação foi o convívio social entre as equipes, conforme depoimento do Entrevistado 7 - Controladoria: 
[..] faço com que o pessoal administrativo busque estar atualizados sobre todos os processos operacionais. Uma das coisas que incentivamos é a o almoço conjunto entre as equipes operacional e financeira. Neste momento muitas experiências pessoais eram compartilhadas, até mesmo como uma "historinha", como uma curiosidade, mas que todo mundo aproveitava como informação para seu dia a dia (Entrevistado 7, Controladoria).

Quanto à transmissão de conhecimento, para 67\% dos profissionais de controladoria ela se dá por meio das reuniões e dos relatórios, sendo que grande parte deles demonstra preocupação na formalização desse conhecimento. Já para os profissionais de operações, $67 \%$ citaram os relacionamentos pessoais como forma de transmissão das informações, identificando, dentre elas, visitas à fábrica e contatos informais como "conversas de corredor", "tomar um café e aproveitar para partilhar conhecimentos" e "bate-papo", o que é corroborado por Mouritsen e Larsen (2005), que citam um ambiente aberto e conversas no café como modo de alavancar ou transformar o conhecimento individual.

Essa informalidade é vista por $56 \%$ dos profissionais de controladoria e, também, pelos os de operações, como um incentivo das empresas na partilha de conhecimentos, pois essas têm o foco na solução de problemas do dia a dia, em "solucionar problemas urgentes", cujo principal entrave ao processo de transmissão de conhecimentos se dá entre as áreas de controladoria e operações.

\subsubsection{Externalização}

Em relação ao item Externalização, metade dos profissionais, tanto os de controladoria, quanto os de operações, consideraram que possuem, individualmente, um nível médio de disposição para propiciar a construção de conhecimentos entre os departamentos. Esses profissionais mostraram que percebem a disposição como um fator importante, porém indicaram que o outro departamento é que não permite maior intensidade na interação, ou por questões de o dia-a-dia serem mais importantes, ou por desconfiar de um controle excessivo por parte do outro departamento, conforme Tabela 5.

Tabela 5
\begin{tabular}{llr} 
Externalização \\
\hline Tipo & Profissional & Externalização \\
\hline Alto & Controladoria & $33 \%$ \\
Alto & Operações & $43 \%$ \\
Médio & Controladoria & $\mathbf{5 2 \%}$ \\
Médio & Operações & $\mathbf{4 6 \%}$ \\
Baixo & Controladoria & $15 \%$ \\
Baixo & Operações & $11 \%$ \\
\hline \multicolumn{7}{l}{ Fonte: Desenvolvido pelos autores, 2017.}
\end{tabular}

Para a não ocorrência da externalização, um respondente da área de controladoria argumentou que: "se você transmite muitos conhecimentos ao pessoal de operações, eles tendem a querem fazer o seu trabalho". Já os profissionais de operações citaram que o tempo é o principal fator que impede o processo de construção de conhecimento com os profissionais de controladoria.

Já o profissional de operações (Entrevistado 17) traz elemento humano como o impeditivo maior, conforme segue: 
[...] a principal dificuldade na construção de conhecimento, é o receio que as pessoas têm de perder algo quando compartilham o conhecimento. Sem dúvida o fator humano sempre será uma restrição neste processo de construção do conhecimento. Por isso, acredito que a empresa com a sua visão, missão e valores tem papel fundamental para instituir a construção de conhecimento entre as áreas. (Entrevistado 17, Operações).

Quanto à transformação de conhecimentos individuais em coletivos entre os departamentos $56 \%$ dos profissionais de controladoria demonstraram que há transformação, porém não houve indicação de que alguma demanda interna tenha sido solucionada pelo departamento de operações. Para os $78 \%$ dos profissionais de operações, entretanto, houve transformação interna realizada pela controladoria, e atribui isso ao fato deste departamento ser o responsável pelo controle e cobrança dos resultados operacionais

Essa transformação ocorre, principalmente, com profissionais de departamento de custos, pois estes apresentam "condições técnicas de opinar e solucionar problemas" com olhos para o impacto financeiro, um exemplo é a fala do Entrevistado 13-Controladoria:

[...] a matéria prima representa cerca de $40 \%$ do custo total dos itens, (então) a área de operações criou uma forma de gestão melhor desses usos, com melhores ferramentas de medição, (e isso) ajudou a controladoria a realizar melhor os controles financeiros. Então nós desenvolvemos em conjunto uma ferramenta para mensuração do consumo das matérias primas e aí foi possível analisar melhor os gastos com perda de processo, o que antes não eram bem controladas. Nessa operação, a controladoria pôde melhorar o controle e custeamento dessa perda. (Entrevistado 13, Controladoria).

Em síntese, pode-se verificar que, de acordo com os profissionais em questão, as reuniões periódicas para verificação de resultado, ou grupos de melhoria ou, ainda, a necessidade para solução de problemas, são os motivadores da externalização do conhecimento.

Adicionalmente, é de se mencionar que, na literatura vários estudos têm focado nas práticas de operações e de controladoria (Bendig, Strese \& Breteel, 2017; Netland, Schloetzer \& Ferdows, 2015), mas que eles têm dado atenção a como essas áreas interagem entre si, indicando a necessidade da realização de estudos integrados (Nisiyama, Oyadomari, Yen-Tsang \& Aguiar, 2016).

\subsubsection{Combinação}

A análise dos resultados sugere que os profissionais consideram a existência de procedimentos formais como a principal ferramenta de combinação, motivada pela necessidade de certificações e governança corporativa. Todavia, conforme Nonaka e Takeuchi, (1997), a existência de outras comunicações como documentos, reuniões, conversas telefônicas ou redes de comunicação computadorizadas, também fazem parte do processo de combinação. Tabela 6 .

Tabela 6

Combinação

\begin{tabular}{llr}
\hline Tipo & Profisssional & Combinação \\
\hline Alto & Controladoria & $\mathbf{4 2 \%}$ \\
Alto & Operações & $\mathbf{4 2 \%}$ \\
Médio & Controladoria & $39 \%$ \\
Médio & Operações & $36 \%$ \\
Baixo & Controladoria & $19 \%$ \\
Baixo & Operações & $22 \%$ \\
\hline
\end{tabular}

Fonte: Desenvolvido pelos autores, 2017. 
Quanto ao acesso do conhecimento na forma de repositórios, nota-se que o diálogo é mais utilizado, que o acesso ao repositório pelo interessado, conforme se pode observar por meio da fala do Entrevistado 14 Operações.

[...]. Não basta apenas abrir e ler o repositório, é necessário entender e seguir uma série de passos para o desenvolvimento do que você quer, e da forma que você quer. [...] normalmente as pessoas preferem falar comigo do que ter que buscar as informações no repositório, mesmo estando pronto. Falando é mais rápido. Muitas vezes o pessoal acaba telefonando e fica mais fácil de resolver o problema. Normalmente eu explico, mas sempre digo que para mais informações ele tem que ler o repositório. (Entrevistado 14, Operações).

Quanto à construção de procedimentos em conjunto, cerca da metade dos profissionais de controladoria e de operações respondeu que isso ocorre às vezes, e apenas em caso de necessidade. Apesar disso, quando são necessários esses conhecimentos, ficam disponíveis e podem ser vistos entre os departamentos avaliados ou conhecidos através de comunicação pessoal.

Os respondentes demonstraram, também, que compreendem que a informação disponível é importante, porém que isso nem sempre existe sem uma necessidade específica. Com base nessas afirmações, observou-se que para $61 \%$ dos profissionais de ambas as áreas, a redundância na disponibilização das informações é importante, podendo indicar novamente que a busca por elas ocorre em momentos e situações de necessidade.

Os entrevistados também mencionaram que há "problemas de compreensão" em muitos documentos criados, gerando "questionamentos desnecessários", denotando que há preocupação no julgamento que outros departamentos podem fazer quanto à qualidade ou à importância de determinadas tarefas de uma equipe.

Quanto à percepção da importância de se conhecer as tarefas do outro departamento, houve predomínio de mais respostas para um nível alto de percepção, visto que, $78 \%$ dos profissionais de controladoria e $67 \%$ dos profissionais de operações, consideram importantes, consoante os depoimentos que seguem:

[...]. Se você não conhece o negócio, você não pode atuar coerentemente, você não pode entender ou interagir, até porque a pessoa da outra área está na frente de trabalho. Se nós da área de controladoria não conhecermos nosso negócio não dá para fazermos as ações necessárias para a sobrevivência da empresa. [...]. Em um projeto, por que um gerente de projeto precisa pagar almoço para cliente, não é apenas a questão do almoço, mas sim uma situação de interação necessária. (Entrevistado 15, Controladoria).

Conhecer as atividades da controladoria é fundamental, pois na controladoria existe um departamento que é fundamental para a empresa, que é o departamento de custos. Esse departamento sempre tem boas lições e informações importantes o bastante para que a gente mude e altere o comportamento dos gestores de fábrica, os gestores técnicos, ao ponto que o departamento mostra através das bases e técnicas de custos como os gestores devem controlar seus gastos, mostrando o que acontece com a margem quando eles derrapam, o que acontece com os produtos e a margem da empresa. Isso é fundamental (Entrevistado 15, Operações).

Profissionais de controladoria mencionaram que a disponibilização de procedimentos aumenta a "capacidade de controle" do trabalho e do resultado gerado pelas operações, conforme a fala do Entrevistado 14 - Controladoria:

Sim, as informações são públicas e estão disponíveis em um sistema de documento, tudo informatizado, onde cada gestor com acesso ao sistema pode olhar o procedimento dos demais. Essa é uma necessidade porque temos uma auditoria interna que faz as verificações de procedimentos conforme nossa atividade e reporta isso para a matriz (Entrevistado 14, Controladoria). 
Já os profissionais de operações, em sua maioria, se preocupam em conhecer os processos de trabalho dos profissionais de controladoria a fim de "verificar como a informação da produção está impactando os dados financeiros".

A literatura disponível mostra que, em relação ao conhecimento e formalização dos procedimentos, tais regras quando escritas levam a um controle maior por parte da área corporativa das empresas sobre todos os processos (Brenner \& Ambos, 2013).

\subsubsection{Internalização}

Em relação ao item Internalização, a análise dos resultados (Tabela 7) mostra que 56\% dos profissionais de controladoria, e $33 \%$ dos de operações, observam um grau de sinergia alto entre os departamentos, mas que, basicamente, essa sinergia está vinculada a solução de problemas e se percebe que o processo de internalização, ou seja, de absorção de uma experiência ocorre muito mais por parte do profissional de controladoria, em relação aos conhecimentos disponibilizados pelo profissional de operações. Os profissionais de controladoria também mencionaram valer-se da "oportunidade gerada pela necessidade de controle" para ter maior disponibilidade de informações dos profissionais de operações.

Tabela 7
\begin{tabular}{llr} 
Internalização \\
\hline Tipo & Profissional & Internalização \\
\hline Alto & Controladoria & $\mathbf{6 4 \%}$ \\
Alto & Operações & $\mathbf{5 6 \%}$ \\
Médio & Controladoria & $28 \%$ \\
Médio & Operações & $31 \%$ \\
Baixo & Controladoria & $8 \%$ \\
Baixo & Operações & $14 \%$ \\
\hline Fonte: & Desenvolvido pelos autores, 2017.
\end{tabular}

Visto ao exposto, entende-se que o profissional de operações está mais concentrado na criação de conhecimento interno do departamento e que o de controladoria, por conhecer o trabalho de operações, legitima ainda mais seu posicionamento de controlador, fato que está em linhas com a literatura, vez que muito tem sido escrito e discutido sobre o papel do controller nas organizações contemporâneas (Järvenpää, 2007; Wolf et al., 2015; Mack \& Goretzky, 2017). Qual é o estilo e quais atitudes são desejáveis de tal profissional? Essa pergunta ainda não tem uma resposta clara, vez que estudos que tratam de tal tema ainda são incipientes (Järvenpää, 2007). Alguns autores têm discutido que um estilo mais brando é o mais propício, uma vez que profissionais em controladoria tentam influenciar os gestores de operações a tomarem certas medidas desejáveis pela liderança (Mack \& Goretzky, 2017).

Nas entrevistas, os profissionais de operações não demonstraram grande interesse em internalizar conhecimentos mais específicos da controladoria. Dentre as potenciais causas podem ser identificadas a "falta de tempo" e "necessidade de solucionar questões produtivas mais urgentes", conforme relatado pelo Entrevistado 12 - Controladoria:

Quando da implantação do ERP SAP, implantou-se também uma nova realidade operacional, tanto para o pessoal administrativo como para o pessoal operacional. [...]. Como exemplo, o novo sistema não permitia que se emitisse uma Nota Fiscal, se não existisse produto no estoque. [...] O sistema havia sido parametrizado para que a Ordem de Produção fosse fechada apenas no final do dia, quando se apurava o consumo de matérias primas e embalagens. Sem que a Diretoria fosse envolvida, o pessoal administrativo e da produção encontraram uma solução para que os produtos pudessem ser entregues corretamente, usando ações simples e organizadas no processo. (Entrevistado 12, Controladoria). 
Os resultados das interações entre departamentos mostram, em sua maioria, a condição de pôr em prática os conhecimentos adquiridos pelos profissionais, mostrando uma boa capacidade de internalização, conforme o relato do Entrevistado 12 - Operações:

Tivemos um caso de lançamento de toda uma linha de biscoito que só se viabilizava com uma estrutura logística diferenciada, estruturada em conjunto com custos. Outro exemplo são as campanhas de Panetone, que vêm se mostrando cada ano mais lucrativas devido, entre outras ações, a um forte envolvimento da área de custo ao longo da campanha (Entrevistado 12, Operações).

Para 78\% dos profissionais de controladoria, e para $67 \%$ dos profissionais de operações, a aplicação prática é o principal resultado das interações entre pessoas e departamentos. Profissionais de ambas as áreas deram exemplos de interação quanto a "melhorias de processos por intervenção da controladoria", pois esta última tem como objetivo a criação e acompanhamento de metas financeiras, citaram ainda que "profissionais de operações criaram oportunidades de melhoria na criação e compreensão de indicadores de desempenho", questões como "redução custos e melhoria na recuperação de impostos de insumos de fábrica" também foram citadas. Os relatos a seguir, ilustram essa situação:

Quando temos esse contato é bastante produtivo, pois sabemos o quanto está sendo eficaz as ações exercidas pelas áreas, podemos trocar informações e propor ações; [...]. Sempre me surpreendem as ideias que o pessoal de fora da produção nos sugerem muitas vezes. É uma visão de fora que pode ajudar a resolver o problema interno. (Entrevistado 11, Operações)

Sempre gera bons resultados, mas que a princípio não pareça. Por exemplo, em certas discussões vemos que um assunto não andou, mas depois alguém consegue ter uma ideia baseado na discussão que aconteceu. Acho isso normal, nem sempre estamos inspirados na hora. (Entrevistado 11, Controladoria).

\subsection{Construção de Conhecimento Empresarial}

Considerando os aspectos quanto à construção de conhecimento empresarial, verificouse que para $67 \%$ dos profissionais de controladoria e, também, para os de operações, a interação somente existe quando necessário (nível médio). (Tabela 8).

Tabela 8

Construção de conhecimento empresarial

\begin{tabular}{llr}
\hline Tipo & Profissional & Empresa \\
\hline Alto & Controladoria & $41 \%$ \\
Alto & Operações & $36 \%$ \\
Médio & Controladoria & $\mathbf{4 7 \%}$ \\
Médio & Operações & $\mathbf{5 3 \%}$ \\
Baixo & Controladoria & $12 \%$ \\
Baixo & Operações & $11 \%$ \\
\hline
\end{tabular}

Fonte: Desenvolvido pelos autores, 2017.

Pode-se verificar, também, que a maior parte dos profissionais entende como totalmente importante e necessária, a interação com o outro departamento, mas ou a empresa não incentiva claramente essa interação, ou o dia-a-dia se sobrepões a esta necessidade em função de se atingir metas preestabelecidas.

Um exemplo dessa interação não planejada é relatado pelo Entrevistado 9 Controladoria: 
Temos reuniões gerenciais, a cada dois meses, para divulgação de resultado geral, mas temos reuniões mensais com foco no desempenho do último período e de solução de problemas e correção de rotas. Nesta participam todo o pessoal do industrial e supply, além de membros convidados dos grupos de melhoria. Temos também os trabalhos do projeto de S\&OP, onde aproveitamos para trocar informações e conhecimento, pois estamos desenvolvendo todo um trabalho relativamente novo para a empresa. (Entrevistado 9, Controladoria).

Para o profissional de controladoria, melhorar os controles ou processos de mensuração podem ser consideradas como trocas de conhecimento ocorridas em qualquer momento, mas para os profissionais de operações essas medidas ocorrem para melhorar diretamente seu desempenho operacional, consoante a fala do Entrevistado 8 - Controladoria:

É uma interação alta, onde o gerente de operações é uma pessoa preocupada em transformar em resultados tudo o que ele faz, ele é uma pessoa extremamente preocupada com resultados, então ele está constantemente em contato com a controladoria. Não há ação que ele tenha que fazer que ele não consulte a controladoria para compreensão dos reflexos do que ele vai fazer (Entrevistado 8, Controladoria).

\section{Outro exemplo é a fala do Entrevistado 8 - Operações:}

[...] se algo inesperado acontece, eu comunico mesmo que seja com um e-mail rápido. Por exemplo, se alguma linha ficou parada por algum problema, eu já aviso que os indicadores serão piores naquela semana. Como todos ficam sabendo, dá tempo de agir para recuperar os resultados, claro, nem sempre, mas pelo menos conseguimos ter uma previsão mais próxima da realidade. (Entrevistado 8, Operações).

Em síntese, para os profissionais de operações existe o entendimento de que é necessário ocorrer um "treinamento" ou uma ação "formal" para que a criação de conhecimento ocorra, enquanto que para os profissionais de controladoria isso seria possível utilizando-se de "situações de o dia-a-dia".

Em operações, a literatura aponta que é preciso prover os empregados de ferramentais e recursos para que haja o treinamento desses empregados nos princípios que envolvem a mudança e gestão dos processos (Kaynak, 2003).

Apesar da opinião dos profissionais, existem críticas à eficácia da universidade corporativa interna, como na fala do Entrevistado 9 - Operações:

Temos sim uma universidade corporativa interna, sendo que vários profissionais dão esses cursos. Isso é uma forma de partilha de conhecimento, mas os conhecimentos referentes aos projetos e clientes somente são compartilhados de forma reativa [... ]. Há muito conhecimento na empresa que ninguém sabe que existe, está morto lá, às vezes algum solicita algo e outro diz que acha que alguém já fez um projeto sobre aquilo. Mas não há um trabalho efetivo para essas divulgações. (Entrevistado 9, Operações).

Quanto ao posicionamento da empresa, percebeu-se que $78 \%$ das empresas dos profissionais de controladoria, e também dos de operações, não demonstram claramente uma preocupação estratégica quanto a construção de conhecimento entre departamentos.

Os entrevistados deixaram claro, em diversas oportunidades, que a "solução de problemas", "geração de resultado" e "resultado financeiro imediato" são as preocupações recorrentes da empresa. Esse achado está alinhado com a percepção de Von Krogh, Ichijo e Nonaka (2001), que afirmam haver dois processos de criação de conhecimento: um que efetivamente cria novos conhecimentos, o que traz uma contribuição para o avanço da empresa e, outro, que se preocupa em transferir conhecimento, o que faz com que sejam ampliadas as condições de sobrevivência. 
A análise das entrevistas indicou, ainda, que, tanto entre profissionais de controladoria, quanto em profissionais de operações, existe a possibilidade de $56 \%$ de criação futura de conhecimento em suas empresas, mostrando que esses profissionais reconhecem a importância de haver a gestão de conhecimento, mas que atribuem essa lacuna ao outro departamento, ou à falta de incentivo da empresa, sendo que nenhum entrevistado se mostrou como responsável pela falta de interação.

Em resumo, a análise das entrevistas permitiu a chegar às seguintes constatações, em relação à amostra estudada:

a) Os profissionais são atualizados ou capacitados por fontes diversas de informações, como, por exemplo, em cursos, eventos e trocas de experiências com outros profissionais em reuniões.

b) Os profissionais demonstraram uma alta proatividade no uso do ferramental de controladoria e operações, o que está em linha com as pesquisas mais recentes sobre emporwerment, ou empoderamento de empregados (Kennedy \& Widener, 2008). Conceito esse que se refere a dar incentivo aos funcionários para serem proativos e tomarem decisões no dia a dia reduzindo, assim, o suporte direto da gerência (Patterson; West e Wall, 2004).

c) Os profissionais quando se reuniam para trabalhar em equipe, tinham como objetivo uma busca de uma solução para um problema do dia a dia, mais que realmente uma preocupação legitima em compartilhar conhecimento entre as áreas.

d) Os procedimentos internos ligados às tarefas e às atividades nas empresas não estavam disponíveis a todos, o que pode sugerir que os profissionais faziam uma seleção do conhecimento relevante para cada profissão.

e) Os profissionais percebem um alto grau de sinergia entre os departamentos, sendo esta basicamente ligada à busca por solução de problema.

f) A interação foi percebida como fundamental, pois os profissionais entendiam que a aplicação prática do conhecimento e resultado desta interação entre os departamentos.

g) O aprender fazendo é inerente ao processo de internalização, visto que os profissionais sugeriram que a área de controladoria demonstrava capacidade de adquirir conhecimento de operações de modo não prático, mas em um nível capaz de auxiliar a resolver os problemas do dia a dia.

h) $\mathrm{O}$ momentum da necessidade de criação de conhecimento foi percebido de modo diferente entre ambos profissionais, sendo os profissionais de controladoria fortemente motivados por troca de conhecimento para melhora de seus indicadores de desempenho.

i) A distância física entre os profissionais foi apontada como um entrave a uma melhor colaboração para a criação de conhecimento entre ambas as áreas. No entanto o ambiente de operações era percebido como propicio a tal prática.

j) A maior parte dos profissionais percebem que a colaboração em busca da construção do conhecimento pode melhorar as atividades da empresa.

k) Não foi identificada uma preocupação estratégica quanto ao posicionamento da empresa em relação à construção do conhecimento entre os departamentos.

\section{Considerações Finais}

Este estudo teve por objetivo avaliar a interação entre profissionais das áreas controladoria e de gestão de operações, sob a luz da teoria da criação de conhecimento na 
empresa de Nonaka e Takeuchi. Para tanto, foram entrevistados 8 (oito) profissionais de controladoria e de operações, pares da mesma empresa, tendo como base um roteiro estruturado. As respostas foram analisadas por meio do software de análise qualitativa de dados (QDA) NVIVO.

Os principais achados do estudo foram elencados no item anterior. Todavia, vale destacar que os resultados revelam que ambos profissionais se preocupam com a qualidade do conhecimento individual e que este é necessário e importante para a transmissão de conhecimento entre as equipes. Isso denota, por um lado, que esses profissionais estão dispostos a oferecer trabalhos de alto nível e, por outro lado, que é necessário que as empresas ofereçam suporte aos profissionais para desempenharem seu trabalho com alto padrão de qualidade.

Os profissionais também demonstraram que eles e suas equipes têm condições de absorver conhecimento entre os departamentos, com preocupações na solução de problemas de ordem imediata. Nesse caso, seria importante garantir que esse foco em resolução de problemas não se limite a atender às questões imediatas, mas, sim, que se crie uma cultura para também se pensar em médio e longo prazos.

Outro aspecto relevante a se destacar é que em diversas falas verificou-se que a interação entre esses profissionais é percebida como benéfica para a empresa, mas a preocupação com a perda de poder é um fator a ser trabalhado no campo da prática. Iniciativas que promovam a interação informal foram bastante citadas como facilitadores desse processo, além da necessidade de um entendimento dos negócios por parte dos profissionais de controladoria, e uma necessidade que os profissionais de operações entendam os impactos financeiros de suas decisões.

Por fim, vale mencionar que a construção de conhecimento empresarial é uma preocupação dos profissionais respondentes, mas que as suas habilidades podem não ser suficientes para gerar tal conhecimento, pois estão ocupados em resolver problemas de curto prazo. A falta de um direcionamento efetivo da empresa nesse sentido, combinada com a percepção de perda de poder, podem contribuir para que essa construção de conhecimento não ocorra. De fato, nas empresas não foi encontrado um modelo de governança, assim como uma institucionalização da socialização e criação de tal conhecimento. Nesse caso, a implantação de um comitê, ou grupo de discussões, poderia ser uma forma de se visar a perpetuação do conhecimento empresarial.

Assim sendo, entende-se que este estudo traz importantes contribuições para a literatura e para a prática profissional ao revelar como pensam e agem profissionais de controladoria e de operações, quanto à criação do conhecimento em suas empresas, mostrando que ainda existem sensíveis dificuldades na criação do conhecimento empresarial, a despeito de sua relevância.

\section{Referências}

Abernethy, M.A., Horne, M., Lillis, M.A., Malina, M.A \& Selto, F. H. (2005) A multi-method approach to building causal performance maps from expert knowledge. Contemporary Accounting Research, 16(2), 135-155. (https://doi.org/10.1016/j.mar.2005.03.003).

Ahrens, T., \& Chapman, C. (2002) The structuration of legitimate performance measures and management: day-to-day contests of accountability in a UK restaurant chain. Management Accounting Research, 13(2), 151-171 (https://doi.org/10.1006/mare.2001.0187).

Antunes, M. T. P. (2004). A influência dos investimentos em capital intelectual no desempenho das empresas: um estudo baseado no entendimento de gestores de grandes empresas brasileiras. Tese (Doutorado em Ciências Contábeis), FEA/USP, São Paulo. 
Bartel, C., \& Dutton, J. (2001) Ambiguous organizational memberships: Constructing organizational identities. In: Hogg, M.A. \& Terry, D.J. (eds.). Social identity processes in organizational contexts, Philadelphia. Psycology Press, 115-130.

Bendig, D., Strese, S., \& Brettel, M. (2017) The link between operational leanness and credit ratings. Journal of Operations Management, 52, 46-55, 2017. Disponível em:

(http://dx.doi.org/10.1016/j.jom.2016.11.001).

Beuren, I. M. (Org). 2006 Como elaborar trabalhos monográficos em Contabilidade - Teoria e Prática. $3^{\text {a }}$ ed. São Paulo: Atlas.

Brenner, B., \& Ambos, B. (2013) A question of legitimacy? A dynamic perspective on multinational firm control. Organization Science, 24(3), 773-795, 2013. (

https://doi.org/10.1287/orsc.1120.0760).

Burns, J., \& Baldvinsdottir, G. (2005) An institutional perspective of accountants' new rolesthe interplay of contradictions and praxis. European Accounting Review, 14(4), 725-757.

Byrne, S., \& PIerce, B. (2007) Towards a more comprehensive understanding of the roles of management accountants. European Accounting Review, 16(3), 469498.(https://doi.org/10.1080/09638180701507114).

Caldwell, R. (2003) The Changing Roles of Personnel Managers: Old Ambiguities, New Uncertainties. Journal of Management Studies, 40(4), 983-1004.

(https://doi.org/10.1111/1467-6486.00367).

Cornman, M. A. (2008) The perceived utility of accounting support by operation managers. 2008. 145 f. Dissertação (Degree of Doctor off Philosophy applied Management and Decision Sciences). College of Management and Tecnology, Walden University.

Davenport, T. H., \& Prusak, L. (1998) Conhecimento empresarial: Como as organizações gerenciam o seu capital intelectual. $8^{\mathrm{a}}$ ed. Rio de Janeiro: Elsevier.

Davis, T. R. V., \& Mclaughlin, L. P. (2009) Is Finance a Business Partner Yet? Strategic Finance, $\quad 90 \quad$ (9), 35-40. Disponível em: $<$ http://search.proquest.com.ezproxy.auckland.ac.nz/docview/229798394/fulltextPDF/8A6C0 9F22EB84897PQ/1?accountid=8424>.

Donoghue, A., Fayard, G., Brigham, N. (1998) Masters of Information: How the Top Controllers Add Value. Financial Executive, 14(2), 25-27. Disponível em: $<$ http://search.ebscohost.com/login.aspx?direct=true\&db=bth\&AN=11873592\&site=ehostlive $>$.

Drejer, A., Blackmon, K., \& Voss, C. (2000) Worlds apart? - a look at the operations management area in the US, UK and Scandinavia. Scandinavian Journal of Management, 16, (1), 45-66.

Fauré, B., \& Rouleau, L. (2011) The strategic competence of accountants and middle managers in budget making. Accounting, Organizations and Society, 36(3), 167-182.

Fullerton, R.R., Kennedy, F.A.,Widener, S.K. (2014) Lean manufacturing and firm performance: The incrementalcontribution of lean management accounting practices. Journal of Operations Management, 32, (7-8), 414-428. 
Frezatti, F., Rocha, W., Nascimento, A. R., \& Junqueira, E. (2009) Controle Gerencial: uma abordagem da contabilidade gerencial no contexto econômico, comportamental e sociológico. $1^{\text {a }}$ ed. São Paulo: Atlas.

Gollan, P. J., Kalfa, S., Agarwal, R., Green, R., \& Randhawa, K. (2015) Lean manufacturing as a high-performance work system : the case of Cochlear. International Journal of Production Research, 7543, December, 6434-6447.

Grandey, A. A. (2003) When "the show must go on": Surface acting and deep acting as determinants of emotional exhaustion and peer-rated service delivery. Academy of management Journal, 46(1), 86-96. (https://doi.org/10.2307/30040678).

Granlund, M., \& Lukka, K. (1998) It's a small world of management accounting practices. Journal of management accounting research, 10, 153.

Hopper, T. M. (1980) Role conflicts of management accountants and their position within organisation structures. Accounting, Organizations and Society, 5(4), 401-411.

Hu, X., \& Shi, J. (2015) Employees' surface acting in intereactions with leader and peers. Journal of Internet Banking and Commerce, 36(8), 1132-1152.

Huang, T. A., Stewart, R. A., \& Chen, L. (2010) Identifying key enablers to improve business performance in Taiwanese electronic manufacturing companies. International Journal of Operations \& Production Management, 30(2), 155-180. Disponível em: $<$ http://www.emeraldinsight.com/doi/10.1108/01443571011018699>.

Hülsheger, U. R., \& Schewe, A. F. (2011) On the costs and benefits of emotional labor: A metaanalysis of three decades of research. Journal of Occupational Health Psychology, 16(3), 361389.

Järvenpää, M. (2007) Making business partners: a case study on how management accounting culture was changed. European Accounting Review, 16(1), 99-142.

Kaynak, H. (2003) The relationship between total quality management practices and their effects on firm performance. Journal of Operations Management, 21(4), 405-435.

Kennedy, F. A., Widener, S. K. (2008) A control framework: Insights from evidence on lean accounting. Management Accounting Research, 19, 301-323.

Krajewski, L. J., Ritzman, L. P., \& Malhotra, M. K. (2010) Operations Management: Processes and Supply Chains. 9. ed. Upper Saddle River NJ: Prentice Hall.

Krippendorff, K. (2013) Content Analysis: An introduction to its methodology. Sage, Third Eddtion, 2013.

Lambert, C., \& Sponem, S. (2005) Corporate governance and profit manipulation: a French field study. Critical perspectives on accounting, 16(6), 717-748.

Mack, S., \& Goretzki, L. (2011) Qualitative Research in Accounting \& Management Article information. Qualitative Research in Accounting \& Management, 13(3), 328-362.

Marques, K.C.M., \& Rocha, W. (2017 agosto) Construção de conhecimento sobre target costing: uma análise de pesquisas sobre fatores que aumentam a sua adoção e uso. Revista Contemporânea de Contabilidade, Florianópolis, 14(32), 03-20.

Martins, P., \& Laugeni, F.P. (2010) Administração da Produção. São Paulo: Saraiva. 
Meredith, J.R., Steward, M.D., \& Lewis, B.R. (2011) Knowledge dissemination in operations management: Published perceptions versus academic reality. Omega, 39(4), 435-446. (https://doi.org/10.1016/j.omega.2010.10.003).

Morales, J., \& Lambert, C. (2013) Dirty work and the construction of identity. An ethnographic study of management accounting practices. Accounting, Organizations and Society, 38(3), 228244.

Mouritsen, J., \& Larsen, H. T. (2005) The 2nd wave of knowledge management: The management control of knowledge resources through intellectual capital information. Management Accounting Research, 16, 371-394.

Netland, T. H., Schloetzer, J. D., \& Ferdows, K. (2015) Implementing corporate lean programs: The effect of management control practices. Journal of Operations Management, 36, 90-102. Disponível em: <http://dx.doi.org/10.1016/j.jom.2015.03.005>.

Nisiyama, E. K., Oyadomari, J. C. T., Yen-Tsang, C., \& Aguiar, A. B. (2015) O Uso dos Sistemas de Controle Gerencial e Técnicas de Gestão Operacional. Brazilian Business Review, 13(2), 57-83, 2015.

Nonaka, I., \& Takeuchi, H. (1997) Criação de conhecimento na empresa - Com oas empresas japonesas geram a dinâmica da inovação. $20^{\mathrm{a}} \mathrm{ed}$. Rio de Janeiro: Elsevier.

Patterson, M. G., West, M. A., \& Wall, T. D. (2004) Integrated manufacturing, empowerment, and company performance. Journal of Organizational Behavior, 25(5), 641665 .

Paulsson, G. (2012) The role of management accountants in new public management. Financial Accountability \& Management, 28(4), 378-394.

Sabbag, P.Y. (2007) Espirais do conhecimento: ativando individuos, grupos e organizações. São Paulo: Saraiva.

Simãozinho, S.M., Oyadomari, J. C. T, Barros, M. H., Akamine, C., Antunes, M. T. P.(2015) Modelo SECI e "BA" de Nonaka e Takeuchi aplicado à area de controladoria. Revista Eletrônica de Administração e Turismo-ReAT, 6(3), 557-576.

Souza, G. H. C. (2016) Perfil dos Controllers no Brasil: beans counters versus business partners. Dissertação (Mestrado em Ciências Contábeis)- Universidade Federal de Pernambuco, RecifePE.

Tazelaar, F., \& Snijders, C. (2013) Operational risk assessments by supply chain professionals: Process and performance. Journal of Operations Management, 31(1-2), 37-51.

Von Krogh, G., Ichijo, K, \& Nonaka, I. (2001) Bringing care into knowledge development of business organizations. In: Nonaka, I, \& Nishiguchi, T. (eds.). Knowledge emergence: Social, technical, and evolutionary dimensions of knowledge creation. Oxford University Press, 3052.

Wright, C. (2009) Inside out? Organizational membership, ambiguity and the ambivalent identity of the internal consultant. British Journal of Management, 20(3), 309-322. (https://doi.org/10.1111/j.1467-8551.2008.00585.x). 